\title{
Articles
}

\section{Measuring clinical performance and outcomes from diabetes information systems: an observational study}

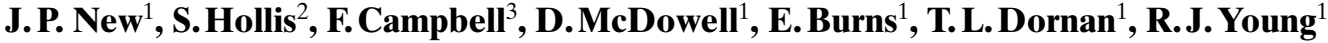 \\ ${ }^{1}$ Department of Diabetes, Hope Hospital, Salford, UK \\ ${ }^{2}$ Medical Statistics Unit, Department of Mathematics and Statistics, Lancaster University, UK \\ ${ }^{3}$ Statistician, Research and Development Unit, Hope Hospital, Salford, UK
}

\section{Abstract}

Aims/hypothesis. To examine changes in diabetes care provision after the introduction of a district diabetes information system.

Methods. All patients with diabetes registered on the system between 1993 and $1998(n=6544)$ were included in the analysis. Drop-out cohort analysis was used to handle population changes, logistic regression models with general estimating equations were used to examine changes in clinical performance over time.

Results. After the introduction of the system, care processes improved appreciably, in both primary and secondary care. The proportion of patients receiving a preventative care review within the calendar year rose from $56 \%$ in 1993 to $67 \%$ in 1998 . The proportion of these in whom each process was completed improved in all categories from 1993 to 1998: blood pressure $96 \%$ to $98 \%$; glycaemic check $67 \%$ to $93 \%$; lipid check $31 \%$ to $68 \%$; renal check $46 \%$ to $87 \%$; fundoscopy $79 \%$ to $92 \%$; foot screen $87 \%$ to $87 \%$. Similarly there was an increase in the proportion of patients achieving intermediate outcome treatment targets $\left(\mathrm{HbA}_{1 \mathrm{c}} \leq 9.0 \%\right.$ from $29 \%$ to $43 \%$; cholesterol $\leq 5.5 \mathrm{mmol} / 15 \%$ to $19 \%$; blood pressure $\leq 160 / 9037 \%$ to $46 \%$ ).

Conclusion/interpretation. Our results suggest appreciable improvements in diabetes care between 1993 and 1998. These changes apply to an entire population of patients across primary and shared care. We believe that these improvements could, in part, be attributable to the way in which the district diabetes information system has facilitated the structured cascade of diabetes care. [Diabetologia (2000) 43: 836-843]

Keywords Diabetes mellitus, information systems, care provision, disease management, structured care.
A population-based district diabetes information system (DDIS) has been operational in Salford in the United Kingdom for 7 years. We have investigated whether data, collected in the DDIS during routine clinical practice can be used for clinical quality performance monitoring and whether the introduction of the DDIS has influenced diabetes care.

Received: 20 January 2000 and in revised form: 20 March 2000

Corresponding author: Dr J.P. New, Department of Diabetes and Endocrinology, Hope Hospital, Stott Lane, Salford M6 $8 \mathrm{HD}, \mathrm{UK}$

Abbreviations: DDIS, District diabetes information system; GEE, generalised estimating equations
Diabetes is a large and costly healthcare problem $[1,2]$. There is abundant evidence that preventative care is effective in minimising the adverse and costly outcomes $[3,4]$. To apply this knowledge in clinical practice is however, a formidable and as yet largely unrealised task $[5,6]$. In response to this challenge we initiated, in 1988, a guideline-based district-wide integrated diabetes care programme. The aim was to improve the processes and outcomes of diabetes care throughout Salford. The programme was directed by a district diabetes liaison committee comprising primary, secondary and community diabetes health care personnel, health authority and patient representatives. In 1992, this was supplemented by a DDIS designed to support guideline implementation. It prompts the key processes of care (annual review, 
Table 1. Definition of key processes and intermediate outcome targets

\begin{tabular}{|c|c|c|}
\hline Key process & Definition & Targets \\
\hline Weight check & Weight recorded & \\
\hline Blood pressure check & Systolic and diastolic blood pressure recorded & $\begin{array}{l}\text { systolic } \leq 160, \text { diastolic } \leq 90 \mathrm{mmHg} ; \\
\text { systolic } \leq 140 \text {, diastolic } \leq 80 \mathrm{mmHg}\end{array}$ \\
\hline Eye check & Dilated fundoscopy recorded (as conducted) & \\
\hline Foot check & Neurovascular foot examination recorded (as conducted) & \\
\hline Glycaemic check & $\mathrm{HbA}_{1} \mathrm{c}$ or glucose recorded & $\mathrm{HbA}_{1} \mathrm{c} \leq 9.0 \% ; \mathrm{HbA}_{1} \mathrm{c} \leq 7.0 \%$ \\
\hline Lipid check & Cholesterol recorded & cholesterol $\leq 5.5 \mathrm{mmol} / 1$ \\
\hline
\end{tabular}

fundal examination, measurement of glycaemic control etc.), facilitates their documentation and provides regular feedback to practices, clinics and the district diabetes liaison committee on key processes and intermediate outcomes.

Because it is difficult to apply simple statistics to the complex operational data from the DDIS we sought appropriate statistical techniques, capable of handling such data, to analyse changes in diabetes care provision over time. This study examines the changes in key processes and intermediate outcomes of diabetes care since the introduction of the DDIS.

\section{Subjects and methods}

DDIS operational arrangements. Salford is an urban district in Greater Manchester in the United Kingdom, with a population of 230,510. Approximately $50 \%$ of electoral wards are moderately or severely deprived (Jarman index $>30$ ) [7]. Less than $5 \%$ of the population is of non-European ethnicity. The DDIS was introduced in January 1992 and is used by all primary care and hospital diabetes services. Records based upon the United Kingdom diabetes dataset [8] are updated and verified during the annual structured preventative care review, the content of which was defined in the district guidelines introduced in 1988. The guidelines specify thresholds for referral to, and discharge from, shared care with the hospital diabetes centre based upon: achievement and stability of glycaemic, blood pressure and lipid targets; presence of diabetes-related complications and the use of insulin. Patients attending the diabetes centre are deemed to have received "shared care" and the preventative care review is then the responsibility of the hospital team. Other patients are treated and reviewed in primary care.

A standardised, single page, pro-forma is used to prompt the 'key processes' of annual review (weight, blood pressure, measurement of glycaemic control, retinal screen, foot examination etc). The form is generated before the annual review and shows any previously recorded complications and the preceding four biochemical and clinical results.

Biochemical data are directly transferred from the biochemistry department. The results of eye screening by optometrists are returned to the data manager of the DDIS and entered manually. Final outcome data, such as amputations, myocardial infarction and retinal laser photocoagulation are validated yearly, by linking the details recorded on DDIS with outpatient and inpatient episodes coded on local hospital information systems [9].
Operational links have been established with all general practices and hospital diabetes clinics to ensure smooth flows of data to and from the clinical teams.

Aggregated, anonymised benchmarks are distributed to practices and clinics three times a year. Practices receive summaries of their annual review processes rates, intermediate outcome results, and target ranges. The content is linked to an ongoing programme of multidisciplinary professional education, covering various aspects of diabetes care over a 2-year cycle.

Process definitions. Patients were classified as being available to receive structured preventative diabetes care in a given calendar year if they were alive, living within Salford district (defined by postcode) and diagnosed as having diabetes. These patients were the denominator for calculating the percentage receiving annual review. Achievement of annual review was defined as an entry in any of the fields identifying a clinical contact: blood pressure; weight; foot examination; fundoscopy (excluding those done by optometrists, as they are only responsible for a single aspect of diabetes care). Those patients where only biochemical measurements were available, with no record of any other aspect of structured diabetes care, were not considered to have had an annual review. Key processes and targets for intermediate outcomes are listed in Table 1. Targets for glycaemic control, cholesterol and blood pressure were defined in the local guidelines in 1988 as: $\mathrm{HbA}_{1 \mathrm{c}} 9 \%$ or less (normal range $<6.0 \%$ ) ; total cholesterol $5.5 \mathrm{mmol} / \mathrm{l}$ or less, systolic blood pressure $160 \mathrm{mmHg}$ or less and diastolic blood pressure $90 \mathrm{mmHg}$ or less.

Statistical methods. The data consist of repeated measurements over a number of years, in a changing population. Ignoring this structure in the analysis could produce misleading conclusions; standard errors will generally be underestimated, leading to overestimates of statistical significance. General estimating equations (GEE) can be used to allow for this structure in an extension of generalised linear models such as logistic regression $[10,11]$. A GEE model includes estimates of the correlation of outcomes within a subject and allows the calculation of robust estimates for the standard errors of regression coefficients. Provided that the basic generalised linear model for the average response is correct and that there is no correlation in the outcomes between subjects, the use of robust standard errors ensures consistent inference even if the correlation structure is not correctly specified. Models were fitted in SPLUS version 3.4 (MathSoft, Cambridge Mass., USA), the Oswald library being used to implement GEE (software and documentation available from the Oswald website [12]). No restrictions were placed on the form of the correlation matrix. 


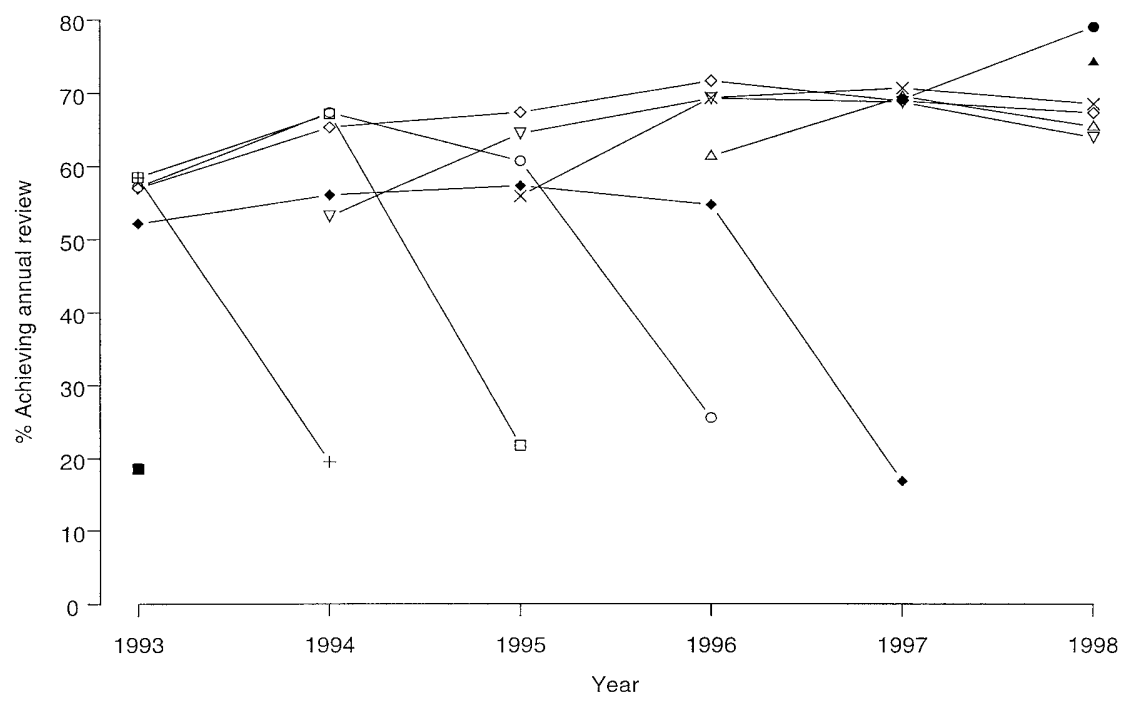

Fig. 1. Percentage of patients within Salford achieving annual structured preventative diabetes review. Individual cohorts are identified with similar symbols across time

Odds ratios were calculated by comparing each year to the previous year. All fitted rates are standardised to the 1998 rates of place of care and type of diabetes.

\section{Results}

Patients included in analysis. In 1992, the first year, only a small number of annual reviews were recorded on the DDIS, particularly for primary care patients, possibly due to under-recording of reviews while clinicians became familiar with the new system. To include data from 1992, therefore, might over emphasise the degree of any subsequent change. Accordingly we have analysed the data starting from 1993, when use of the system had become routine, to 1998.

A total of 7141 patients were registered on the DDIS between 1993 and 1998. Of these 597 (8.4\%), although registered, had no record of year of diagnosis or type of diabetes and were excluded due to insufficient information. The following analysis therefore includes 6544 patients, of whom 3472 (53\%) were available throughout the entire study period. Each year an average of 230 patients $(86 \%$ died, $14 \%$ moved away) left the DDIS and 401 were added. In $1998,55 \%$ of patients received shared care $[16 \%$ Type I (insulin-dependent), 39\% Type II (non-insulin-dependent) diabetes mellitus; mean age 42 and 62 respectively] and $45 \%$ were treated in primary care only (1\% Type I, $44 \%$ Type II; mean age 48 and 68 , respectively).

Key process achievement rates. The proportion of patients receiving annual review increased steadily from $55 \%$ in 1993 to $68 \%$ in 1998 . These figures could, however, be misleading as they are based on different subjects each year. Of the 4538 patients available for review in 1993, 1149 had left the DDIS (moved or died) by 1998 and 2006 new patients were added (moved into the area or newly diagnosed). One common method of dealing with missing longitudinal data is "complete case analysis" where patients who do not have data at all time points are excluded from the analysis. This is inefficient; in our data only $3472(53 \%)$ patients were available for review for the entire period.

We therefore grouped the patients according to their availability for review between 1993 and 1998 (availability cohorts). Patients were considered to belong to a cohort according to the successive years that they were available for annual review. The proportion of patients receiving annual review each year, by cohort, are displayed in Figure 1. This allows trends to be safely interpreted, as each cohort contains the same subjects at all time points. A pronounced reduction in annual review becomes apparent for the final year of each cohort, which could not be deduced from the overall attendance rates, illustrating the advantage of availability cohorts in highlighting trends and patterns. Obviously the final year of a cohort can only be identified retrospectively when, for the following year, the patient is recorded as having died or moved away. Consequently no cohorts end in 1998.

Generalised estimating equations (GEE) were used to allow for within-patient correlations across time, i. e. if a patient has good glycaemic control one year, it is likely to be good the following year. Using logistic regression and GEE, the odds of attendance for review were modelled, adjusted for both type of diabetes and place of care, which showed a relative increase of $67 \%$ from 1993 to 1998 [Odds ratio (OR) $1.67,95 \%$ CI 1.54 to 1.80 ]. A more clinically meaningful picture is provided by applying these fitted 


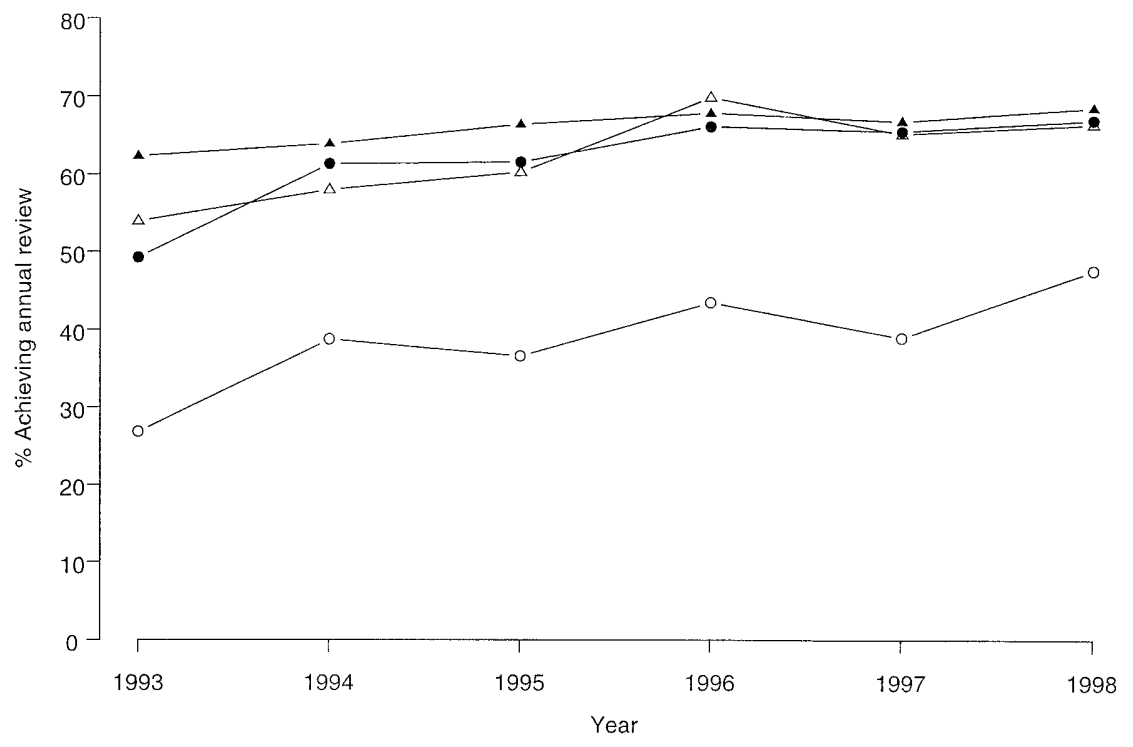

Fig. 2. Achievement of annual review according to location of care (primary care $\bigcirc$, shared care $\triangle$ ) and type of diabetes (Type I open symbols, Type II filled)

odds to a relevant population (i.e. all patients present in 1998) producing standardised annual rates of review, increasing from $55 \%$ in 1993 to $67 \%$ in 1998 (Table 2). Similar patterns of change were seen in patients with Types I and II diabetes, receiving either primary or shared care (Fig. 2). The rates of achievement of review within 2-year periods increased from $77 \%(1993 / 1994)$ to $83 \%(1997 / 1998)$. When data from the final year of each cohort were excluded ( $n=1090$ potential reviews), only minor changes were seen in the results.

Clinical processes done during annual review, (weight, blood pressure, fundoscopy and foot exami- nation) and biochemical measurements, are presented for all patients and for those patients with a documented review (Fig. 3). The standardised rates and odds ratios for process achievement are shown in Tables 2 and 3. For glycaemic check, neurovascular foot examination and dilated fundoscopy there were clinically significant improvements in process measurements between 1993 and 1994 which then remained high and stable.

For patients receiving an annual review, blood pressure measurements were very well recorded throughout (Table 2, Fig.3). Both foot examination and fundoscopy improved statistically significantly between 1993 and 1994 (87\% to $96 \%, 79 \%$ to $93 \%$, respectively). The increased fundoscopy rates were generally maintained throughout the study, whereas foot examination rates returned to initial levels. Initial renal and lipid screening performance was poor but there were clinically significant yearly improve-

Table 2. Achievement of review and process measurements, standardised to the 1998 rates of type of diabetes and location of care

\begin{tabular}{|c|c|c|c|c|c|c|c|}
\hline \multirow[t]{2}{*}{ Year } & \multirow{2}{*}{$\begin{array}{l}\text { Review } \\
\text { Rate (\%) } \\
\text { OR }(95 \% \text { CI) }\end{array}$} & \multicolumn{3}{|c|}{$\begin{array}{l}\text { Based on patients undergoing annual review } \\
\text { ( } 5906 \text { patients, } 19283 \text { reviews) }\end{array}$} & \multicolumn{3}{|c|}{$\begin{array}{l}\text { Based on all patients eligible for annual review } \\
\text { (6544 patients, } 30086 \text { reviews) }\end{array}$} \\
\hline & & $\begin{array}{l}\text { Blood pressure } \\
\text { Rate }(\%) \\
\text { OR }(95 \% \text { CI })\end{array}$ & $\begin{array}{l}\text { Fundoscopy } \\
\text { Rate }(\%) \\
\text { OR }(95 \% \text { CI })\end{array}$ & $\begin{array}{l}\text { Foot } \\
\text { Rate }(\%) \\
\text { OR }(95 \% \mathrm{CI})\end{array}$ & $\begin{array}{l}\text { Blood pressure } \\
\text { Rate }(\%) \\
\text { OR }(95 \% \text { CI })\end{array}$ & $\begin{array}{l}\text { Fundoscopy } \\
\text { Rate }(\%) \\
\text { OR }(95 \% \text { CI })\end{array}$ & $\begin{array}{l}\text { Foot } \\
\text { Rate (\%) } \\
\text { OR }(95 \% \text { CI })\end{array}$ \\
\hline 1993 & $55.2 \%$ & $95.9 \%$ & $78.6 \%$ & $87.0 \%$ & $52.9 \%$ & $43.9 \%$ & $48.2 \%$ \\
\hline 1994 & $\begin{array}{l}61.5 \% \\
1.30(1.21,1.39)\end{array}$ & $\begin{array}{l}97.1 \% \\
1.41(1.06,1.89)\end{array}$ & $\begin{array}{l}93.1 \% \\
3.72(3.16,4.37)\end{array}$ & $\begin{array}{l}96.1 \% \\
3.65(2.95,4.52)\end{array}$ & $\begin{array}{l}59.7 \% \\
1.32(1.23,1.42)\end{array}$ & $\begin{array}{l}57.3 \% \\
1.72(1.60,1.85)\end{array}$ & $\begin{array}{l}59.2 \% \\
1.56(1.45,1.68)\end{array}$ \\
\hline 1996 & $\begin{array}{l}67.2 \% \\
1.20(1.12,1.29)\end{array}$ & $\begin{array}{l}96.5 \% \\
0.73(0.55,0.97)\end{array}$ & $\begin{array}{l}89.7 \% \\
0.82(0.70,0.96)\end{array}$ & $\begin{array}{l}85.7 \% \\
0.81(0.71,0.93)\end{array}$ & $\begin{array}{l}64.8 \% \\
1.16(1.08,1.23)\end{array}$ & $\begin{array}{l}60.2 \% \\
1.11(1.04,1.18)\end{array}$ & $\begin{array}{l}57.6 \% \\
1.08(1.01,1.16)\end{array}$ \\
\hline 1997 & $\begin{array}{l}65.7 \% \\
0.93(0.87,0.99)\end{array}$ & $\begin{array}{l}98.1 \% \\
1.88(1.42,2.50)\end{array}$ & $\begin{array}{l}90.9 \% \\
1.14(0.99,1.32)\end{array}$ & $\begin{array}{l}88.0 \% \\
1.21(1.07,1.38)\end{array}$ & $\begin{array}{l}64.4 \% \\
0.98(0.92,1.05)\end{array}$ & $\begin{array}{l}59.6 \% \\
0.97(0.91,1.04)\end{array}$ & $\begin{array}{l}57.8 \% \\
1.00(0.94,1.07)\end{array}$ \\
\hline
\end{tabular}

The odds ratios (OR) are calculated relative to the rate in the previous year 


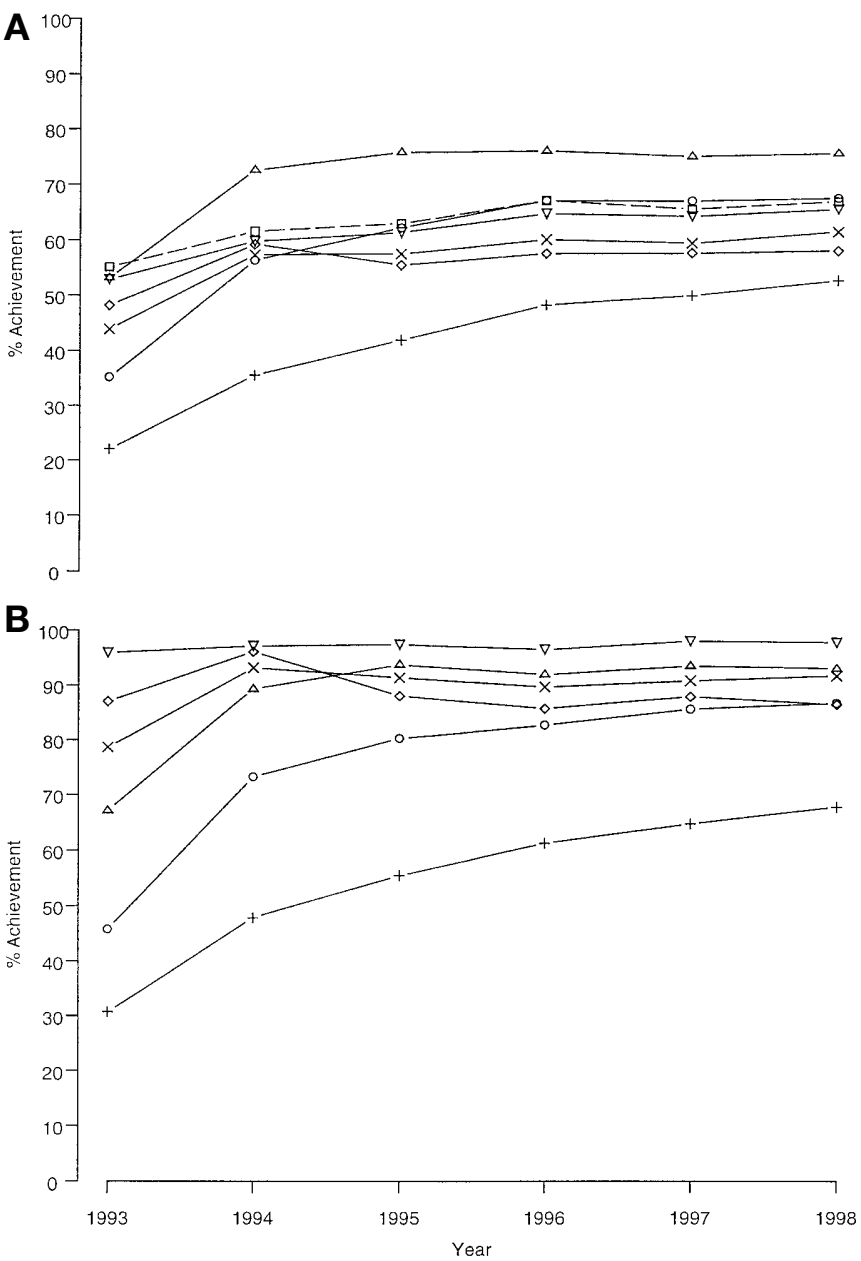

Fig.3A,B. Percentage of patients receiving key process measurements (review $\square$ (dashed line), glycaemic $\triangle$, lipid + , renal $\bigcirc$, blood pressure $\nabla$, fundoscopy $\times$, foot $\diamond)$, standardised to the 1998 rates of type of diabetes and location of care. Results in $\mathbf{A}$ are based on all patients eligible for review and in $\mathbf{B}$ on patients undergoing annual review

ments (Table 3, Fig. 3). Similar improvements occurred in both primary and shared-care patients.

When all eligible patients were considered, clinical process performance rates reflected the combined improvements of both annual review and measurement rates achieved during review. Consequently, greater improvements for all aspects of diabetes care were seen. Biochemical screening was often done independently of clinical review and so rates greater than that of annual review were observed, particularly for glycaemic measurements. For weight measurement the results were very similar to blood pressure (data not shown).

Intermediate outcomes. All patients available for review were included; if a measurement was not recorded it was assumed that the target had not been achieved. The yearly standardised percentage achievement of targets for glycated haemoglobin, cholesterol and blood pressure are shown in Table 4 and Figure 4. For cholesterol and both blood pressure target levels, there were small but steady improvements throughout the study. The greatest improvements were seen between 1993 and 1994. For glycated haemoglobin there was no obvious pattern of change.

\section{Discussion}

This study shows a method of analysis and presentation for data collected routinely during preventative care. Since introducing the diabetes information system there have been statistically significant improvements in annual review, process measurement and intermediate outcomes.

The approaches to improving diabetes care within Salford, facilitated by the DDIS, have focused on a cascade of improving the number of patients receiving annual review, increasing process achievement rates, and increasing the proportion achieving metabolic treatment targets. Within this framework, we can examine the quality of diabetes care by considering each step of the cascade in turn.

The first step of the cascade is improvement of annual review rates. The rates of review have increased statistically significantly during the study period, from $55 \%$ to $67 \%$. This improvement was seen mainly within the first 4 years, thereafter review rates remained fairly static. Although a substantial minority of patients are not reviewed each year, $83 \%$ of eligible patients were reviewed within the 2-year period, 1997/1998, suggesting that most patients receive regular, if not annual, diabetes review. There was a pronounced reduction in the rate of annual review in the last year during which the patient was available. This could be due to patients moving or dying within the calendar year, reducing opportunity for review.

Process achievement rates can be calculated as the percentage of reviews that include each process measurement. This allows feedback to clinicians on the second step of the cascade, their performance within annual reviews. From a population-based viewpoint, it is, however, important to also examine the percentage of eligible patients receiving the processes of diabetes care, irrespective of whether they attend for annual review. We therefore present achievement rates of process measurements both for those patients reviewed and for all eligible patients.

Process measurement rates during annual review improved during the first 2 years of the study, most notably in areas of poorest initial performance. From 1995 onwards, more than $80 \%$ of patients attending annual review underwent each of the key process measurements, with the exception of cholesterol. When all eligible patients were considered, process measurement rates reflected the combined improvements in annual review and in measurement 
Table 3. Achievement of review and process measurements, standardised to the 1998 rates of type of diabetes and location of care

\begin{tabular}{|c|c|c|c|c|c|c|}
\hline \multirow[t]{2}{*}{ Year } & \multicolumn{3}{|c|}{$\begin{array}{l}\text { Based on patient undergoing annual review } \\
\text { (5906 patients, } 19283 \text { reviews) }\end{array}$} & \multicolumn{3}{|c|}{$\begin{array}{l}\text { Based on all patients eligible for annual review } \\
\text { ( } 6544 \text { patients, } 30086 \text { reviews) }\end{array}$} \\
\hline & $\begin{array}{l}\text { Glycaemic } \\
\text { Rate }(\%) \\
\text { OR }(95 \% \text { CI })\end{array}$ & $\begin{array}{l}\text { Lipid } \\
\text { Rate (\%) } \\
\text { OR }(95 \% \mathrm{CI})\end{array}$ & $\begin{array}{l}\text { Renal } \\
\text { Rate (\%) } \\
\text { OR }(95 \% \text { CI) }\end{array}$ & $\begin{array}{l}\text { Glycaemic } \\
\text { Rate }(\%) \\
\text { OR }(95 \% \text { CI })\end{array}$ & $\begin{array}{l}\text { Lipid } \\
\text { Rate (\%) } \\
\text { OR }(95 \% \text { CI })\end{array}$ & $\begin{array}{l}\text { Renal } \\
\text { Rate }(\%) \\
\text { OR }(95 \% \mathrm{CI})\end{array}$ \\
\hline 1993 & $67.1 \%$ & $30.7 \%$ & $45.8 \%$ & $53.1 \%$ & $22.0 \%$ & $36.4 \%$ \\
\hline 1994 & $\begin{array}{l}89.3 \% \\
4.41(3.80,5.12)\end{array}$ & $\begin{array}{l}47.8 \% \\
2.08(1.88,2.31)\end{array}$ & $\begin{array}{l}73.2 \% \\
3.31(2.96,3.70)\end{array}$ & $\begin{array}{l}72.5 \% \\
2.35(2.19,2.53)\end{array}$ & $\begin{array}{l}35.5 \% \\
1.96(1.80,2.12)\end{array}$ & $\begin{array}{l}58.7 \% \\
2.41(2.23,2.60)\end{array}$ \\
\hline 1996 & $\begin{array}{l}92.0 \% \\
0.76(0.63,0.90)\end{array}$ & $\begin{array}{l}61.3 \% \\
1.27(1.16,1.39)\end{array}$ & $\begin{array}{l}82.7 \% \\
1.18(1.04,1.32)\end{array}$ & $\begin{array}{l}76.2 \% \\
1.01(0.95,1.08)\end{array}$ & $\begin{array}{l}48.3 \% \\
1.29(1.21,1.38)\end{array}$ & $\begin{array}{l}68.3 \% \\
1.24(1.16,1.33)\end{array}$ \\
\hline 1997 & $\begin{array}{l}93.6 \% \\
1.27(1.07,1.51)\end{array}$ & $\begin{array}{l}64.8 \% \\
1.16(1.06,1.27)\end{array}$ & $\begin{array}{l}85.7 \% \\
1.25(1.11,1.41)\end{array}$ & $\begin{array}{l}75.2 \% \\
0.94(0.88,1.01)\end{array}$ & $\begin{array}{l}50.1 \% \\
1.07(1.00,1.14)\end{array}$ & $\begin{array}{l}66.1 \% \\
0.99(0.93,1.06)\end{array}$ \\
\hline
\end{tabular}

The odds ratios (OR) are calculated relative to the rate in the previous year

Table 4. Intermediate target achievement rates, standardised to the 1998 rates of type of diabetes and location of care

\begin{tabular}{llllll}
\hline Year & Cholesterol $\leq 5.5 \mathrm{mmol} / 1$ & $\mathrm{HbA}_{1} \mathrm{c} \leq 9.0 \%$ & $\mathrm{HbA}_{1} \mathrm{c} \leq 7.0 \%$ & $\begin{array}{l}\text { Systolic BP } \leq 160 \text { and } \\
\text { Diastolic BP } \leq 90 \mathrm{mmHg} \\
\text { Rate }(\%)\end{array}$ & $\begin{array}{l}\text { Systolic BP } \leq 140 \text { and } \\
\text { Diastolic BP } \leq 80 \mathrm{mmHg} \\
\text { Rate }(\%)\end{array}$ \\
& Rate $(\%)$ & Rate $(\%)$ & Rate $(\%)$ & OR $(95 \% \mathrm{CI})$ \\
\hline & OR $(95 \% \mathrm{CI})$ & $\mathrm{OR}(95 \% \mathrm{CI})$ & $\mathrm{OR}(95 \% \mathrm{CI})$ & $\mathrm{OR}(95 \% \mathrm{CI})$ & $15.9 \%$ \\
1993 & $4.6 \%$ & $29.3 \%$ & $12.5 \%$ & $36.5 \%$ & $19.3 \%$ \\
1994 & $8.1 \%$ & $42.4 \%$ & $18.3 \%$ & $42.3 \%$ & $1.26(1.15,1.39)$ \\
& $1.83(1.56,2.15)$ & $1.78(1.64,1.92)$ & $1.58(1.42,1.75)$ & $1.27(1.18,1.37)$ & $20.3 \%$ \\
1995 & $10.9 \%$ & $40.2 \%$ & $16.6 \%$ & $42.9 \%$ & $1.05(0.97,1.15)$ \\
& $1.38(1.23,1.56)$ & $0.91(0.85,0.97)$ & $0.88(0.81,0.96)$ & $1.02(0.95,1.09)$ & $18.9 \%$ \\
1996 & $13.3 \%$ & $50.8 \%$ & $25.2 \%$ & $43.5 \%$ & $0.91(0.84,0.99)$ \\
& $1.25(1.13,1.39)$ & $1.54(1.44,1.64)$ & $1.71(1.57,1.86)$ & $1.02(0.95,1.09)$ & $20.6 \%$ \\
1997 & $14.1 \%$ & $44.8 \%$ & $17.6 \%$ & $44.8 \%$ & $1.11(1.02,1.20)$ \\
& $1.06(0.96,1.17)$ & $0.78(0.73,0.83)$ & $0.62(0.57,0.67)$ & $1.05(0.98,1.12)$ & $23.4 \%$ \\
1998 & $19.1 \%$ & $43.3 \%$ & $14.4 \%$ & $46.0 \%$ & $1.18(1.09,1.27)$ \\
\hline
\end{tabular}

$\mathrm{BP}=$ blood pressure

The odds ratios (OR) are calculated relative to the rate in the previous year

rates achieved during review. Consequently, greater improvements for all aspects of diabetes care were seen.

Although process rates have generally improved, it is important to examine quality as well as quantity. The third step of the cascade is achievement of improvements in metabolic control. An accurate picture of achievement rates is only possible if metabolic measurements are available for all patients, which does not occur. It is possible that those patients more easily engaged in the annual review programme have better metabolic control. Thus by restricting analysis to these patients, improvements in annual review rates, by including less compliant patients, could appear to worsen target achievement rates. Consequently, if a measurement is not recorded, we instead assume that the target has not been achieved. This gives a conservative estimate of performance, which is applicable to the entire diabetic population. Increases in annual review rates lead to less conservative estimates, unless all those additionally reviewed fail to meet the target. However, we feel that this method is preferable as it rewards, rather than penalises, improvements in review rates.

The final step in the cascade is the reduction of diabetes-related complications. There is abundant evidence that improvements in metabolic control reduce complication rates $[3,4]$. We anticipate that the improvements observed in diabetes care will lead to reduced complications in the longer term. We already have some evidence that our amputation [9] and blindness rates [13] are lower than those reported in similar districts.

The use of cohort analysis and generalised estimating equations to interpret changes in clinical datasets can reliably highlight real changes in clinical 


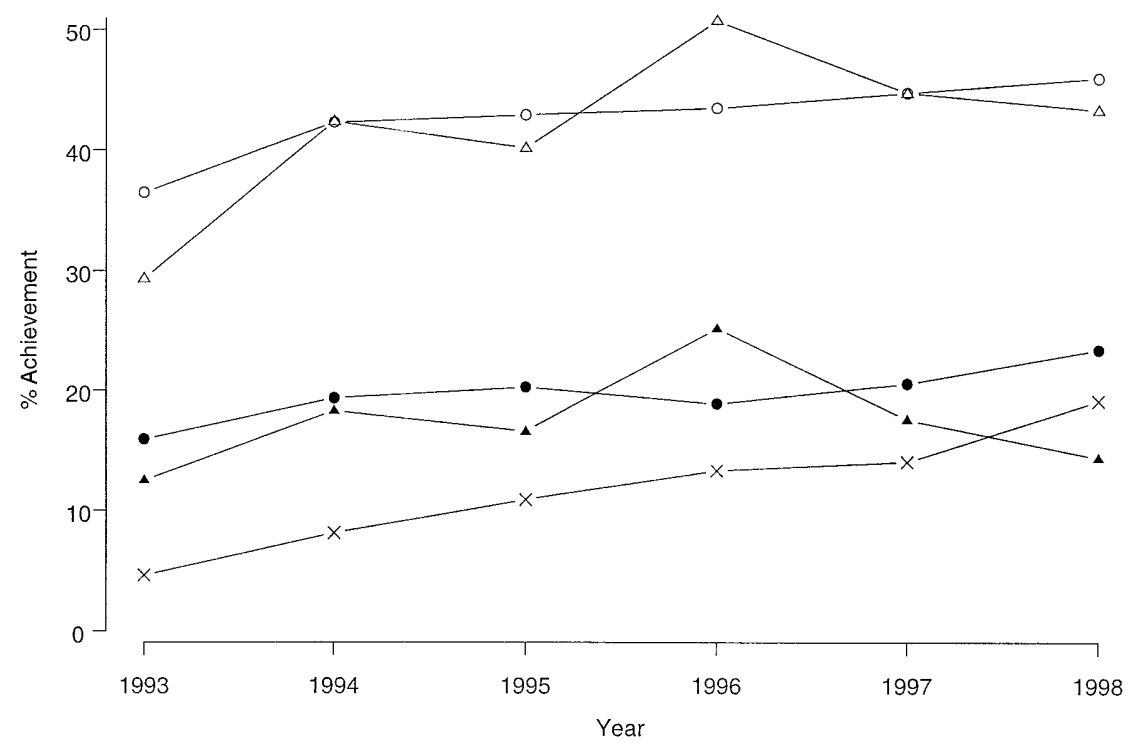

Fig.4. Percentage of patients achieving the targets of $\mathrm{HbA}_{1 \mathrm{c}} \leq 7.0 \%(\boldsymbol{\Delta})$ or $\leq 9.0 \%(\triangle)$; blood pressure $\leq 140 /$ $80 \mathrm{mmHg}$ (O) or $\leq 160 / 90 \mathrm{mmHg} \quad(\bigcirc)$ and cholesterol $\leq 5.5 \mathrm{mmol} / \mathrm{l}(\mathrm{X})$, standardised to the 1998 rates of type of diabetes and location of care

performance over time. Such information is essential for the evaluation of diabetes care. Data from a DDIS typically consist of repeated measurements on a large number of subjects. Dichotomous rather than continuous measurements are common, such as achievement of review, achievement of defined processes, and target achievement. Data are inevitably missing due to the changing population of people with diagnosed diabetes, missed or delayed reviews and incomplete recording of procedures during reviews. These aspects pose problems in the statistical analysis and interpretation of such data. To produce results from DDIS data that reflect genuine changes in clinical performance, sophisticated methods of data analysis are necessary and careful consideration must be given to the assumptions made about missing data and their implications for interpretation. There is no foolproof method of handling missing data. We believe that the methods we have used represent an improvement on traditional approaches and that the choices made when handling the missing data have been optimised for our aim of measuring clinical performance. Such analysis is increasingly important in the era of routine clinical performance monitoring and clinical governance.

Attributing changes in diabetes care to the introduction of a DDIS are inevitably difficult. A controlled comparison of a similar district, operating to the same guidelines, but without a DDIS, would allow any improvements in care to be more confidently attributed to the DDIS. Unfortunately such a comparison would not be practicable for several reasons. Firstly, district-wide policies for the provision of diabetes care vary widely within the United Kingdom. Although they have the same general aims they have subtle differences in the types of tests done (i.e. $\mathrm{HbA}_{1 \mathrm{c}}, \mathrm{HbA}_{1}$, fructosamine), the recommended frequency of testing and more importantly the desired targets. Achievement of targets is especially difficult for glycaemic control because $\mathrm{HbA}_{1 \mathrm{c}}$ results vary greatly according to the methods used. Secondly, and more importantly, it would be practically impossible to extract adequate data, relating to process measurement and the results of biochemical testing, from a non-computerised system. Consequently it would not be possible to draw valid comparisons with a district not using a DDIS.

Is it possible to identify why the changes measured thus far have occurred? By 1992 we already had established guidelines, integrated care structures, shared care working arrangements, and continuous local profession education in diabetes care [14]. Clinical performance was, however, still poor. After the introduction of the DDIS some key processes improved almost immediately but in others change has been more gradual.

The introduction of the DDIS altered our practice in a number of ways, each of which could have been important. Firstly, a structured diabetes pro forma was introduced, which prompts the key processes of structured preventative care and displays previous data. Secondly, all care providers receive regular feedback of performance data, including aggregated anonymised peer group comparisons. Finally, we have linked the process of continuing professional education and development to deficiencies within the cascade of structured care highlighted by results from the DDIS. The use of a variety of interventions, such as audit and feedback, automated recall and re- 
minders have been shown to be effective in influencing clinical performance and health outcomes [15, 16]. Although there have been considerable improvements, in both process measurement and target achievement rates, further improvements are still required if we are to substantially reduce diabetesrelated complications.

Our results suggest appreciable improvements in diabetes care within Salford between 1993 and 1998. Furthermore, these changes apply to an entire population of patients across primary and shared care, not selected groups of patients or enthusiast professionals [5]. We believe that these improvements could, in part, be attributable to the way in which the district diabetes information system has facilitated the structured cascade of diabetes care.

\section{References}

1. King's Fund (1996) Counting the cost: The real impact of non insulin dependent diabetes. British Diabetic Association, London

2. Currie CJ, Kraus TD, Morgan CL, Gill L, Stott NCH, Peters JR (1997) NHS Acute sector expenditure for diabetes: the present, future, and excess in-patient cost of care. Diabet Med 14: 686-692

3. UKPDS (1998) Intensive blood-glucose control with sulphonylureas or insulin compared with conventional treatment and risks of complications in patients with type 2 diabetes (UKPDS 33). Lancet 352: 837-854

4. Diabetes Control and Complications Research Group (1993) The effects of intensive treatment of diabetes on the development and progression of long-term complica- tions in insulin dependent diabetes mellitus. N Engl J Med 329: 977-986

5. Greenhalgh T (1998) Meta-analysis is a blunt and potentially misleading instrument for analysing models of service delivery. B Med J 317: 395-396

6. Orchard T (1998) Diabetes: a time for excitement and concern. BMJ 317: 691-692

7. Jarman B (1983) Identification of underprivileged areas. Br Med J Clin Res Ed 286: 1705-1709

8. Vaughan NJ, Home PD (1995) The UK Diabetes Dataset: a standard for information exchange. Diabetes Audit Working Group of the Research Unit of the Royal College of Physicians. British Diabetic Association. Diabet Med 12: 717-722

9. New JP, McDowell D, Burns E, Young RY (1998) The problem of amputations in patients with newly diagnosed diabetes. Diabet Med 15: 760-765

10. Burton P, Gurrin L, Sly P (1989) Extending the simple linear regression model to account for correlated responses: An introduction to generalized estimating equations and multi-level mixed modelling. Stat Med 17: 1261-1291

11. Zeger SL, Liang K-Y (1986) Longitudinal data analysis for discrete and continuous outcomes. Biometrics 42: 121-130

12. Smith DM (1997) Object oriented Software for the Analysis of Longitudinal Data. Web site http://www.maths.lancs.ac.uk/Software/Oswald/

13. Kaushal K, New JP, McDowell D, Young LB, Taylor R, Young RY (1998) Visual Outcome after laser treatment for diabetic retinopathy. Diabet Med [Suppl 2]: A138

14. Greenhalgh PM (1994) Shared Care for diabetes - a systematic review. Royal college of General Practitioners, London

15. Grol R (1997) Beliefs and evidence in changing clinical practice. BMJ 312: 418-421

16. Oxman AD, Thomson MA, Davis DA, Haynes RB (1995) No magic bullets: a systematic review of 102 trials of interventions to improve professional practice. CMAJ 153: 1423-1431 